ISSN 2073-4352

www.mdpi.com/journal/crystals

\title{
Communication
}

\section{Iodine Molecules Included in the Structure of Dibenzo-24-Crown-8, $\left(\mathrm{I}_{2}\right) @(\mathrm{db24c8})$}

\section{Christine Walbaum, Ingo Pantenburg and Gerd Meyer *}

Department für Chemie, Universität zu Köln, Greinstraße 6, D-50939 Köln, Germany; E-Mails: walbaum2000@yahoo.de (C.W.); ac118@uni-koeln.de (I.P.)

* Author to whom correspondence should be addressed; E-Mail: gerd.meyer@uni-koeln.de; Tel.: +49-221-470-3262; Fax: +49-221-470-5083.

Received: 15 August 2011; in revised form: 20 September 2011 / Accepted: 27 September 2011 / Published: 28 September 2011

\begin{abstract}
A reaction of $\mathrm{YI}_{3}$, dibenzo-24-crown-8 and iodine in ethanol yielded, as a by-product, red single crystals of $\left(\mathrm{I}_{2}\right) @(\mathrm{db} 24 \mathrm{c} 8)$. In the triclinic crystal, $P-1, a=485.0(1)$, $b=1203.7(3), c=1280.4(2) \mathrm{pm}, \alpha=64.56(2)^{\circ}, \beta=86.82(2)^{\circ}, \gamma=83.89(2)^{\circ}$, $V=671.1(2) \times 10^{6} \mathrm{pm}^{3}, Z=1, R_{1}=0.0301$ for 1965 reflections with $\mathrm{I}_{0}>2 \sigma\left(\mathrm{I}_{0}\right)$, iodine molecules with an I-I distance of $268.39(7) \mathrm{pm}$, slightly longer than in the gas phase, are included in a matrix of $\mathrm{db} 24 \mathrm{c} 8$ molecules.
\end{abstract}

Keywords: iodine; dibenzo-24-crown-8; inclusion compound; crystal structure

\section{Introduction}

Dibenzo-24-crown-8 ( $\mathrm{db} 24 \mathrm{c} 8)$ is a large crown ether which may encapsulate rather large cations in a nest-like conformation, such as in $[\mathrm{K}(\mathrm{db} 24 \mathrm{c} 8)]\left(\mathrm{I}_{3}\right)$ [1]. Three of these molecules may also form the second coordination shell of the large cation $\left[\mathrm{Y}\left(\mathrm{H}_{2} \mathrm{O}\right)_{8}(\mathrm{db} 24 \mathrm{c} 8)_{3}\right]^{3+}$ in which the first coordination sphere is built from eight water molecules. This cation was recently found in the polyiodide salt $\left[\mathrm{Y}\left(\mathrm{H}_{2} \mathrm{O}\right)_{8}(\mathrm{db} 24 \mathrm{c} 8)_{3}\right]_{2}\left(\mathrm{I}_{3}\right)_{3}\left(\mathrm{I}_{5}\right)_{3}[1]$. In the course of the reactions that led to this mixed tri-/pentaiodide, we have also observed a small amount of red needles which turned out to be of the inclusion compound $\left(\mathrm{I}_{2}\right) @(\mathrm{db} 24 \mathrm{c} 8)$. Similar inclusion compounds of halogens and common polyethers seem not to be known. However, there are inclusion compounds of polyethers with compounds that are capable 
of forming hydrogen bonds, as for example in $(\mathrm{PicH})_{2}(\mathrm{db} 24 \mathrm{c} 8)$ [2] $(\mathrm{PicH}=$ picric acid) and $\left[\mathrm{Y}\left(\mathrm{NO}_{3}\right)_{3}\left(\mathrm{H}_{2} \mathrm{O}\right)_{3}\right](\mathrm{db} 24 \mathrm{c} 8)[3]$.

\section{Results and Discussion}

The crystal structure of $\left(\mathrm{I}_{2}\right) @(\mathrm{db} 24 \mathrm{c} 8)$ is triclinic, space group $P-1$, with a pseudo-hexagonal unit cell, $a=485.0(1), b=1203.7(3), c=1280.4(2) \mathrm{pm}, \alpha=64.56(2)^{\circ}, \beta=86.82(2)^{\circ}, \gamma=83.89(2)^{\circ}$, hence with $a_{\text {hex }}=b_{\text {hex }} \rightarrow b \approx c, c_{\text {hex }}=a$; $\alpha_{\text {hex }}=\beta \gamma_{\text {hex }} \rightarrow \beta \approx \gamma \approx 90^{\circ}, \gamma_{\text {hex }} \approx \gamma^{*} \approx 120^{\circ}$. There is one formula unit in the unit cell, the volume amounts to $671.1(2) \times 10^{6} \mathrm{pm}^{3}\left(=\AA^{3}\right)$. One iodine molecule resides in the center of the unit cell, surrounded by four $\mathrm{db} 24 \mathrm{c} 8$ molecules, see Figure 1 . The $\mathrm{I}_{2}$ molecules are stacked almost on top of each other with the shortest intermolecular I-I distance of $485.0(1) \mathrm{pm}=a$. The intramolecular I-I distance is surprisingly short, $268.39(7) \mathrm{pm}$, only slightly larger than in gaseous iodine, $267 \mathrm{pm}$ [4,5], and shorter than in solid iodine at $170 \mathrm{~K}, 271.5(6) \mathrm{pm}$ [6,7]. Shortest distances of I to neighboring $\mathrm{O}$ and $\mathrm{C}$ atoms are 292.8(2) (I1-O4) and 374.7(2) pm (I1-C3), well and far beyond the sum of the van der Waals radii [8], $264(\mathrm{I}+\mathrm{O})$ and $275(\mathrm{I}+\mathrm{C})$ pm, respectively.

Figure 1. Perspective view of the crystal structure of $\left(\mathrm{I}_{2}\right) @(\mathrm{db} 24 \mathrm{c} 8)$ down [100]; ball-and-stick and space-filling models.
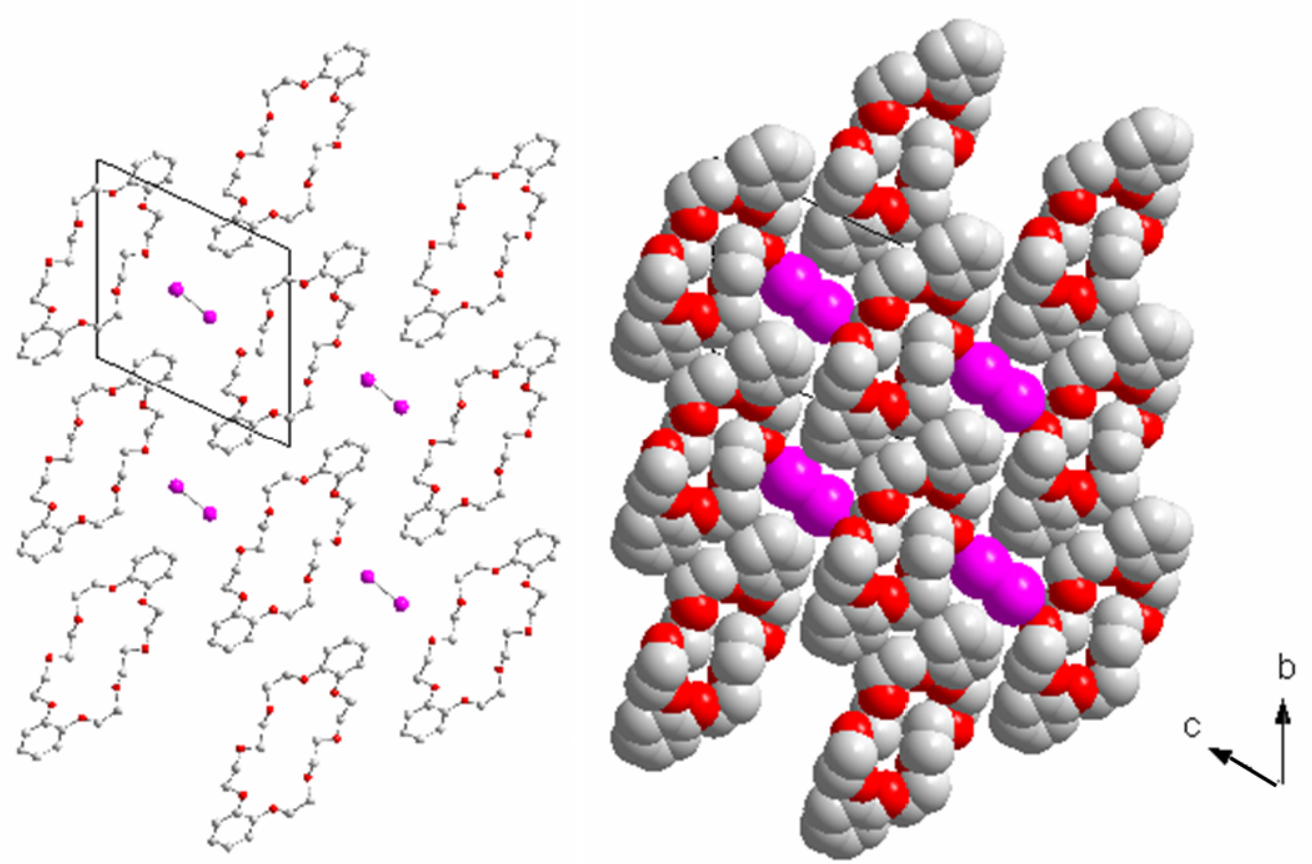

Thus, $\left(\mathrm{I}_{2}\right) @(\mathrm{db} 24 \mathrm{c} 8)$ can be considered as a true inclusion compound. The crystal structure of $\mathrm{db} 24 \mathrm{c} 8$ [9] contains a rather dense peanut packing with a volume per db24c8 molecule of $577 \times 10^{6} \mathrm{pm}^{3}, 94 \times 10^{6} \mathrm{pm}^{3}$ less than the volume of one formula unit of $\left(\mathrm{I}_{2}\right) @(\mathrm{db} 24 \mathrm{c} 8)$. In the crystal structure of iodine [6,7], there are four molecules per unit cell with a cell volume of $327.2 \times 10^{6} \mathrm{pm}^{3}$. One iodine molecule, therefore, affords a volume of $82 \times 10^{6} \mathrm{pm}^{3}$ in solid iodine. In $\left(\mathrm{I}_{2}\right) @(\mathrm{db} 24 \mathrm{c} 8)$, the volume per iodine molecule is, with $94 \times 10^{6} \mathrm{pm}^{3}$, considerably larger. This is in agreement with the more gas-like I-I distance in $\left(\mathrm{I}_{2}\right) @(\mathrm{db} 24 \mathrm{c} 8)$, hence with much less $\left(\mathrm{I}_{2}\right)$ to $(\mathrm{db} 24 \mathrm{c} 8)$ interactions in 
the inclusion compound, compared with those in solid iodine where the shortest intermolecular distances, $353.8 \mathrm{pm}$, are much shorter than twice the van der Waals radius, $2 \times 198=396 \mathrm{pm}$.

Structurally, rows of $\mathrm{db} 24 \mathrm{c} 8$ molecules appear in the [001] direction in the crystal structure of $\mathrm{db} 24 \mathrm{c} 8$, see Figure 2, right. These rows are arranged almost parallel to each other, with a shift according to the angle $\beta=104.93(1)^{\circ}$. The layers that occur parallel (010) are stacked on top of each other in the [010] direction of monoclinic $\mathrm{db} 24 \mathrm{c} 8$. Space for one iodine molecule per $\mathrm{db} 24 \mathrm{c} 8 \mathrm{molecule}$ $\left(\mathrm{I}_{2}\right) @(\mathrm{db} 24 \mathrm{c} 8)$ is provided through some rotation of the $\mathrm{db} 24 \mathrm{c} 8$ molecules and a larger shift of the rows in the [010] direction of $\left(\mathrm{I}_{2}\right) @(\mathrm{db} 24 \mathrm{c} 8)$, see the comparison of the structures in Figure 2.

Figure 2. Comparison of the crystal structures of $\left(\mathrm{I}_{2}\right) @(\mathrm{db} 24 \mathrm{c} 8)$ (left) and $(\mathrm{db} 24 \mathrm{c} 8)$ (right). Views down the short axes, $a=485.0(1)$ and $b=491.3(2) \mathrm{pm}$, respectively.
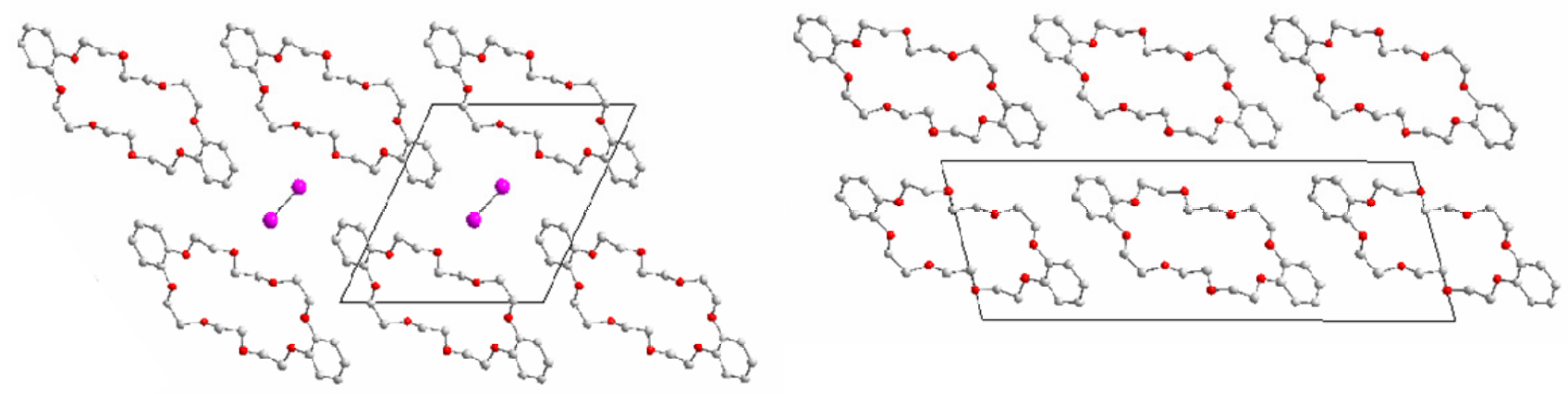

The conformation of the db24c8 molecules in both structures, $\left(\mathrm{I}_{2}\right) @(\mathrm{db} 24 \mathrm{c} 8)$ and the parent (db24c8), and their arrangement in both crystal structures are very similar. This may be seen from Figure 2 and from a comparison of the $\mathrm{db} 24 \mathrm{c} 8$ molecules in both structures as shown in Figure 3 . The $\mathrm{C}-\mathrm{C}$ and $\mathrm{C}-\mathrm{O}$ distances are identical within the error limits.

Figure 3. Comparison of the molecular structures of $\mathrm{db} 24 \mathrm{c} 8$ molecules in the crystal structures of $\left(\mathrm{I}_{2}\right) @(\mathrm{db} 24 \mathrm{c} 8)$ (left) and (db24c8) (right).
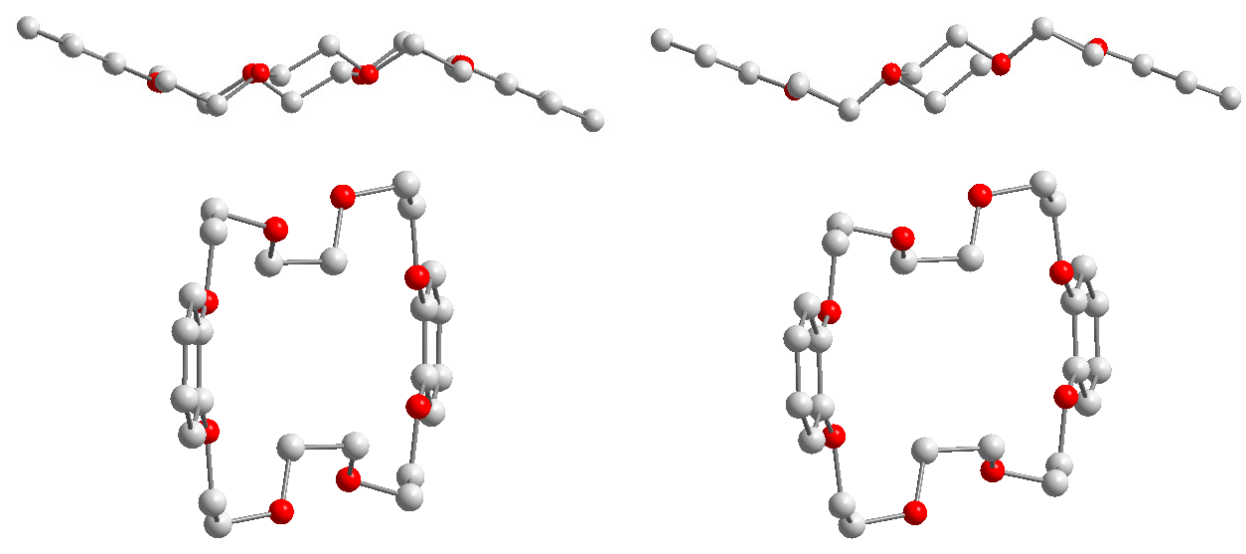


\section{Experimental Section}

In a typical reaction, $0.02 \mathrm{~g}(0.1 \mathrm{mmol})$ yttrium triiodide, $\mathrm{YI}_{3}$, previously synthesized from the elements [10], $0.09 \mathrm{~g}(0.02 \mathrm{mmol})$ dibenzo-24-crown-8 $(\mathrm{db} 24 \mathrm{c} 8)$ and $0.08 \mathrm{~g}(0.3 \mathrm{mmol})$ iodine were dissolved in $40 \mathrm{~mL}$ of ethanol. Slow evaporation of the solvent (beaker with perforated Parafilm ${ }^{\circledR}$ ) yielded single crystals of $\left[\mathrm{Y}\left(\mathrm{H}_{2} \mathrm{O}\right)_{8}(\mathrm{db} 24 \mathrm{c} 8)_{3}\right]_{2}\left(\mathrm{I}_{3}\right)_{3}\left(\mathrm{I}_{5}\right)_{3}$ together with a small amount of $\left(\mathrm{I}_{2}\right) @(\mathrm{db} 24 \mathrm{c} 8)$.

Single crystals were selected under a microscope and sealed in thin-walled glass capillaries. After their quality had been checked by Laue diffraction patterns, the single crystals were transferred to a single-crystal X-ray diffractometer (Stoe Image Plate Diffraction System, IPDS II) to collect a complete intensity data set at ambient temperature. Structure solution and refinement was performed with the programs SHELXS-97 (direct methods) [11,12] and SHELXL-97 [11,13], scattering factors were from International Tables for X-ray Crystallography [14]. Data corrections were carried out for Lorentz and polarization factors and absorption (numerical with the aid of the programs X-RED [15] and X-SHAPE [16]). Further details of the crystal structure determination may be obtained from the Cambridge Crystallography Data center, CCDC-837899, free of charge, on application from CCDC, 12 Union Road, Cambridge CB2 1EZ, UK (fax: +44 $1223 \quad 336033$ or e-mail: deposit@ccdc.cam.ac.uk).

Crystal data for $\left(\mathrm{I}_{2}\right) @(\mathrm{db} 24 \mathrm{c} 8)\left(720.30 \mathrm{~g} \mathrm{~mol}^{-1}\right)$; diffractometer IPDS-II, Stoe, Darmstadt; Mo-K $\alpha$ (graphite monochromator, $\lambda=71.073 \mathrm{pm}$ ); $T=293(2) \mathrm{K} ; 2 \theta_{\max }=59.32^{\circ} ; 180$ images, $0^{\circ} \leq \omega \leq 180^{\circ}$; $\varphi=0^{\circ}, 0^{\circ} \leq \omega \leq 180^{\circ} ; \varphi=90^{\circ}, \Delta \omega=2^{\circ}$; indices: $-5 \leq h \leq 6,-16 \leq k \leq 16,-17 \leq l \leq 17$; transmission $(\min , \max )=0.5359,0.7874 ; \rho_{\text {calc }}=1.738 \mathrm{~g} \mathrm{~cm}^{-3} ; 13396$ reflection intensities measured of which 3765 were symmetrically independent, $R_{\text {int }}=0.0446, \mathrm{~F}(000)=346, \mu=2.387 \mathrm{~mm}^{-1}$. Triclinic, $P-1$ (no. 2), $a=485.0(1), b=1203.7(3), c=1280.4(2) \mathrm{pm}, \alpha=64.56(2)^{\circ}, \beta=86.82(2)^{\circ}, \gamma=83.89(2)^{\circ}$, $V=671.1(2) \times 10^{6} \mathrm{pm}^{3}, Z=1 . R$ values: $\mathrm{R}_{1} / \mathrm{wR}_{2}$ for 1965 reflections with $\left[\mathrm{I}_{0}>2 \sigma\left(\mathrm{I}_{0}\right)\right]: 0.0301 / 0.0625$ and for all data: $0.0804 / 0.0751 ; S_{\text {all }}=0.835$.

\section{Conclusions}

Iodine molecules with I-I distances of $268.39(7) \mathrm{pm}$, between those in gaseous iodine and solid iodine, 267 and $271.5 \mathrm{pm}$, respectively, are included in the solid-state structure of dibenzo-24-crown-8. The molecular structures of the $\mathrm{db} 24 \mathrm{c} 8$ molecules are practically unchanged; there is a volume increase of about $16 \%$ relative to the parent crystal structure of db24c8. This increase amounts to $94 \times 10^{6} \mathrm{pm}^{3}$ which is considerably larger than the volume of $82 \times 10^{6} \mathrm{pm}^{3}$ of an iodine molecule in solid iodine. Only very weak interactions between the iodine and the db24c8 molecules in $\left(\mathrm{I}_{2}\right) @(\mathrm{db} 24 \mathrm{c} 8)$ are thereby attested.

\section{References}

1. Walbaum, C. Neue Poly(inter)halogenide mit Kronenether-stabilisierten Kationen. PhD Dissertation, Universität zu Köln, Köln, Germany, 2009. 
2. Colquhoun, H.M.; Doughty, S.M.; Stoddart, J.F.; Slawin, A.M.Z.; Williams, D.J. Isolation and XRay Crystal Structure of a 2:1 Complex between Picric Acid and Dibenzo-24-crown-8; an Example of a Sandwich Structure. J. Chem. Soc. Perkin Trans. II 1986, 253-257.

3. Lu, T.; Gan, X.; Tan, M.; Yu, K. Studies on Crown Ether Complexes-XXVII. Synthesis, Characterization and Crystal Structure of $\left[\mathrm{Y}_{(}\left(\mathrm{NO}_{3}\right)_{3}\left(\mathrm{OH}_{2}\right)_{3}\right] \cdot($ Dibenzo-24-crown-8). Polyhedron 1993, 12, 621-625.

4. Karle, I.L. Anomalous Electron Scattering from Iodine Vapor. J. Chem. Phys. 1955, 23, 1739-1740;

5. Ukaji, T.; Kuchitsu, K. Effect of Temperature on the Molecular Structure of Iodine Observed by Gas Electron Diffraction. Bull. Chem. Soc. Japn. 1966, 39, 2153-2156.

6. Harris, P.M.; Mack, E.; Blake, F.C. The atomic arrangement in the crystal of orthorhombic iodine. J. Am. Chem. Soc. 1928, 50, 1583-1600.

7. Van Bolhuis, F.; Koster, P.B.; Migchelsen, T. Refinement of the crystal structure of iodine at 110 K. Acta Crystallogr. 1967, 23, 90-91.

8. Bondi, A. Van der Waals Volumes and Radii. J. Phys. Chem. 1964, 68, 441-451.

9. Hanson, I.R.; Hughes, D.L.; Truter, M.R. Crystal and Molecular Structure of 6,7,9,10,12,13,20,21,23,24,26,27-Dodecahydrodibenzo[b, $n][1,4,7,10,13,16,19,22]$ octaoxacyclotetracosin (Dibenzo-24-crown-8). J. Chem. Soc. Perkin Trans. II 1976, 972-976.

10. Meyer, G. Binary Lanthanide(III) Halides, $\mathrm{MX}_{3}(\mathrm{X}=\mathrm{Cl}, \mathrm{Br}, \mathrm{I})$. In Synthesis of Lanthanide and Actinide Compounds; Meyer, G., Morss, L.R., Eds.; Kluwer Acad. Publ.: Dordrecht, The Netherlands, 1991; pp. 135-144.

11. Sheldrick, G.M. A short history of SHELX. Acta Cryst. 2008, A64, 112-122.

12. Sheldrick, G.M. SHELXS-97, Program for Structure Analysis; University of Göttingen: Göttingen, Germany, 1998.

13. Sheldrick, G.M. SHELXL-93, Program for Crystal Structure Refinement; University of Göttingen: Göttingen, Germany, 1993.

14. Wilson, A.J.C. International Tables for Crystallagraphy; Kluwer Acad. Publ.: Dordrecht, The Netherlands, 1992; Volume C.

15. Stoe. X-RED 1.22, Stoe Data Reduction Program (C); Stoe \& Cie GmbH: Darmstadt, Germany, 1999.

16. X-Shape 1.06, Crystal Optimisation for Numerical Absorption Correction (C); Stoe \& Cie GmbH: Darmstadt, Germany, 1999.

(C) 2011 by the authors; licensee MDPI, Basel, Switzerland. This article is an open access article distributed under the terms and conditions of the Creative Commons Attribution license (http://creativecommons.org/licenses/by/3.0/). 